\title{
South Africa's Initiative Towards an Integrated Biodiversity Data Portal
}

\author{
Kiara Ricketts ${ }^{\ddagger}$, Brenda Daly $\ddagger$, Fhatani Ranwashe ${ }^{\ddagger}$, Carol Lefakane ${ }^{\ddagger}$ \\ ‡ SANBI, Cape Town, South Africa
}

Corresponding author: Kiara Ricketts (k.ricketts@sanbi.org.za), Brenda Daly (b.daly@sanbi.org.za), Fhatani Ranwashe (f.ranwashe@sanbi.org.za)

Received: 22 Sep 2021 | Published: 23 Sep 2021

Citation: Ricketts K, Daly B, Ranwashe F, Lefakane C (2021) South Africa's Initiative Towards an Integrated Biodiversity Data Portal. Biodiversity Information Science and Standards 5: e75638.

https://doi.org/10.3897/biss.5.75638

\begin{abstract}
Biodiversity Advisor, developed by the South African National Biodiversity Institute (SANBI), is a system that will provide integrated biodiversity information to a wide range of users who will have access to geospatial data, plant and animal species distribution data, ecosystem-level data, literature, images and metadata. It aims to deliver a centralized location with open access to information to enable research, assessment and monitoring; to support policy development; to foster collaboration and advance governance. Data are aggregated from multiple, diverse data partners across South Africa including, CapeNature, the FitzPatrick Institute of African Ornithology, Iziko South African museum, the National Herbarium of South Africa and the South African Institute for Aquatic Biodiversity.
\end{abstract}

This newly developed and integrated system promotes a shift from tactically-based information systems, aimed at delivering products for individual project initiatives to a strategic system that promotes the building of capacity within organisations and networks. It has been developed by integrating SANBI's existing authoring layers through a serviceorientated architecture approach, which enables seamless cross-platform integration. Some of the key authoring layers that will be integrated are, the Botanical Database of Southern Africa (BODATSA), the Zoological Database of Southern Africa (ZODATSA), the Biodiversity Geographic Information System (BGIS) and SANBI's institutional repository (Opus). Biodiversity Advisor will provide users, policy and decision makers, environmental 
impact practitioners and associated organizations with free access to view, query and download any of South Africa's biodiversity data available on the system, providing them with everything needed to make decisions around conservation and biodiversity planning in South Africa. All sensitive species data, which are those that are vulnerable to collecting, over-exploitation, commercial and/or medicinal use, will be redacted and only granted access upon application.

Biodiversity Advisor will encourage more effective management of data within SANBI, but also encourage the sharing of data by the biodiversity community to provide integrated products and services, which are needed to address complex environmental issues.

\section{Keywords}

biodiversity data repository, decision support system, policy support

\section{Presenting author}

Kiara Ricketts

\section{Presented at}

TDWG 2021 